\title{
Re-Envisioning The Dissertation Stage Of Doctoral Study: Traditional Mistakes With Non-Traditional Learners
}

\author{
Barbara D. Holmes, Argosy University, USA \\ Angela D. Seay, Concordia College, USA \\ Kimberly N. Wilson, Argosy University, USA
}

\begin{abstract}
Doctoral students discuss the shift from learning in isolation to collaborative learning during doctoral study. Pros and cons of learning in isolation and collaborative learning will be detailed with various types of collaboration being discussed.
\end{abstract}

Keywords: Collaboration, cohort, doctoral students

\section{INTRODUCTION}

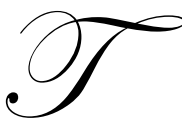

he National Center for Educational Statistics (2004) asserts that enrollments in graduate education will grow by $19 \%$ during the first decade of the new millennium and that most of this growth will be minorities and women. These students are already here in higher education and in For Profit, universities are attracting a disproportionate share of minorities and women to their institutions. This is now the norm in doctoral programs in educational leadership at institutions like Argosy University/Atlanta.

This influx of new learners who are also full-time school leaders has forced institutions to reevaluate the university infrastructure such as course delivery systems, registration systems, advising methods and academic supports. In some cases, courses are taken to the school systems where the students work and delivered in a cohort environment supported by registration and advising teams. Students receive "point of initial contact" support to receive textbooks, plan course matriculation, engage doctoral advisors and participate in computer lab activity. The needs of these "full-time leaders, part-time learners" have dramatically changed the nature of the university and the role of the faculty. Erickson and Howard (2004) assert that "universities are no longer able to overlay traditional programs structures, content and delivery mechanisms" on this new generation of graduate students.

Consequently, that traditional doctoral student who works independently on the dissertation for several years has disappeared as well. The learners in our doctoral program today are fact-paced executives and school change agents who need solutions to the problems facing schools today. They do not have the time to languish over pilot studies of instruments and several years of experiments before they initiate an area of inquiry. They have intimate knowledge of the problems facing schools and the answers that are not yet in evidence. They see students suffering because they cannot read, or write, or compute any acceptable levels of proficiency. These leaders study the subgroups in their schools on a daily basis trying to figure how to get appropriate instructional strategies in place to facilitate better learning. They are in desperate need of action research to help explain the dilemma that schools face in making adequate academic progress. Practical answers, solutions, strategies, and applications that work are needed and needed now.

In his theory of adult learning, Andragogy, Malcolm Knowles (1984) suggest that the adult learner needs to discern immediate value and application in that which is being learned. Knowles suggests:

1. Adults need to be involved in the planning and evaluation of their instruction. 
2. Experience (including mistakes) provides the basis for learning activities.

3. Adults are most interested in learning subjects that have immediate relevance to their job or personal life.

4. Adult learning is problem-centered rather than content-oriented.

With these principles in mind, educational leadership programs must be reflective of practitioner-based learning that makes an immediate and powerful connection between theory and practice. There must be opportunities to apply and evaluate what is being learned. This is especially true for the dissertation experience.

As we studied the needs of these new learners, we discovered that we needed to modify the dissertation stage of the doctoral process. It was out of this discovery learning that the collaborative cohort was developed. This new paradigm of learning controlled for several factors known to cripple traditional doctoral students:

1. Lack of focus on the goal

2. Sense of isolation

3. Lack of support

4. Lack of a shared sense of purpose

\section{LACK OF FOCUS ON THE GOAL}

According to Levine (2002) setting goals is a learned skill, attaining goals is a required skill to become successful. Learners have a desire to attain goals; however, one must prioritize tasks to accomplish any goal. Refusing to prioritize or to plan is a true indication of designing a plan to fail. Developing a feasible plan to navigate successfully through the dissertation stage is required to maintain focus on the goal of completion. George Morrsey once stated, "The plan is actually laying out the sequence of events that have to occur for an individual to achieve a goal."

There are many factors affecting the persistence of doctoral students. Most factors are associated with three specific areas: personal, social, and intellectual. It is imperative to understand why others fail so mistakes and bad practices are not perpetuated. Factors recognized as making a significant impact on the successful completion of a doctoral program were motivational energy, the existence or lack of supportive relationships with faculty and students, time-management, and presence.

Too often, loosing focus of the goal is one of the pitfalls that lead to the direction of becoming a statistic of All-But-Dissertation, (ABD). Once a learner looses focus, it is extremely difficult to acquire success. Bre aux (2003) wrote, "Which way? I stood at a fork in the road, and did not know which way to go, but since I had no destination in mind. If I got there, I'd never know!" Loosing focus of the goal is a traditional mistake that is detrimental to the success of non-traditional learners.

Upon partaking on the responsibility or the determination of obtaining a doctorate degree, individuals have a sense of focus. The idea of beginning the dissertation process ignites excitement of expanding professionally. Given that these learners are full time school leaders, parents, caretakers of extended family members as well as community leaders, the sight of the goal becomes a smeared image that has been dismayed by other life facets. These life facets are also known as external factors. Family obligations have been identified to impede progress and a loss of focus on the goal (Lenz, 1995). Doctorial students begin the program with the goal in mind. However, life's circumstances take president over remaining on track to achieve the goal. When such obstacles are revealed, educators are faced with the decision of becoming ABD or continue to strive to achieve the goal in spite of any extra challenges. Given that the dissertation stage of the doctorial program usually take place with limited communication with program constituents, the educator revert to seizing strength, and support from individuals who have no clue to the endurance of completing the tasks of achieving the goal.

\section{SENSE OF ISOLATION}

The word isolation has a negative connotation, the act of being alone. When taking on the responsibility of writing a dissertation, isolation is not a term that students seek. Attempting to undertake a task, not knowing or 
understanding the ramifications is not a time that is conducive of accepting the challenge of completing the program. Regardless of how detrimental the thought of isolation when embarking on a new endeavor, it is a know factor individuals who reach the dissertation stage and contributes to decisions of becoming a statistic of All-ButDissertation (ABD).

Feelings of isolation also prevent program completion. Studies conducted on finding reasons for attrition among doctoral programs found that isolation remains a prime factor for many students (Hawlery, 2003; Lewis, 2005; Lovitts, 2001). Despite this recognition, the feeling of isolation has yet to be addressed fully in the design of some doctoral programs. Most programs do not include specific features that help to handle this feeling among matriculated students (Bess, 1978; Hawlery, 2003; Lovitts \& Nelson, 2000). Students begin feeling isolated because of confusion about the program and its requirements (Hawlery, 2003).

Before embracing the dissertation stage, learners complete the course work with the guidance of an instructor or professor. Usually, a teacher/student relationship transpires, due to constant communication and collaboration during this process. Traditionally, once students transcend to the first component of dissertation, the student/teacher relationship deceases instantly. Universities require a minimum of one contact per month, whereas previously, during the course of completing the course work, there was constant contact. The learners experience a drastic change, which deviates from normal behavior. Change effect learners differently. However, a combination of drastic change, and fear of the unknown are contributing factors to the traditional mistakes of no-traditional learners.

According to California Postsecondary Education Commission 1990, of the traditional mistakes of nontraditional learners, is learners receiving far less than enough attention from faculty advisors nor supervisor and guidance on the dissertation, as well as lack of support and encouragement from dissertation chairperson and or committee. Green \& Katz (1997) found that students complained of being obligatory to work with chairpersons or advisors with whom individuals had personality conflicts; poor working relationships and or advisors were identified as being uninterested in student's research problems.

Feeling a sense of isolation is a contributing factor that impedes academic success of navigating through the dissertation stage.

\section{LACK OF A STRUCTURED LEARNING ENVIRONMENT}

Structured graduate programs are extremely important to the academic culture of a university, and influence the role in developing effective and efficient scholars. Lack of a structured environment has been a problem for several learners (Kluever, Green, \& Katz 1997). During the dissertation stage, learners are expected to work independently to create new knowledge. Structure is needed to attain the goal of earning a doctorate degree. (Sigafus 1998) found that the absence of structure in a doctoral program left learners confused and uncertain as the dissertation stage took place. University administrators expect students to create their own structure and demonstrate the skill of discipline to complete the process successfully. Educators of K-12 students are usually doctorial candidates, guide, and train students, administrators, and other colleagues on maintaining an equal balance of following a scope and sequence for acquiring knowledge to achieve particular goals. It is difficult to self-train confused and uncertain of the sequence and scope of acquiring knowledge to achieve the goal of completing dissertation stage.

Lack of a structured learning environment is another traditional mistake with non-traditional learners. University leaders expect learners to create the much-needed structure that would be instrumental to success of completing the dissertation stage.

Interaction with the social environment is one of four factors identified as affecting cognitive development (Piaget, 1973). Social interaction is one of the keys to surviving the course work of a doctoral program. Lack of communication between student and advisor is problematic. Regular conversation during the course of the program is necessary. When students work together in the doctoral pursuit, positive benefits are experienced and students are motivated to complete the program. Stinler (2002) states, "We need to create context in which collaborative work can be sustained. Some people think of it is a matter of "finding time"; however, it is also a matter of having a 
program where teachers are able to integrate into the daily routines of school life. In other words, knowing social interaction is a whole-staff process involves trust and common focus with the goal of improving student learning.

\section{SHARED SENSE OF PURPOSE}

Through collaboration and shared realities, university leaders are actively searching for innovative ways for school improvement. This type of organization promotes a culture that fosters shared visions and inclusiveness and enhances a culture of improvement. As interventions and strategies are implemented, the shared vision would focus on the goals of the change process and ensure that the strategies are aligned with the mission of meeting the expectations for student achievement. Hall \& Hord (2001) reported "A supportive school culture decreases the isolation of staff; provides for the continuing increase of its capabilities; nurtures positive relationships among all students; and urges the unceasing quest for increased effectiveness so that all students benefit (p. 193). Additionally, Kouzes \& Posner (2001) stated, "World-class performances are not possible unless there is a strong sense of shared creation and shared responsibilities. Leaders are essential who can skillfully create a climate of trust, facilitate positive interdependence, and support face-to-face interactions" (p. 243). Universities want to produce excellent products. However, administrators are not organizing a shared sense of purpose. It appears as if the system of high education is designed to limit the progress once individuals reaches a certain stage in the process of achieving the goal of completing dissertation.

Through implementation of cohorts and collaborative groups, the university will promote a culture for academic excellence Freed, Klugman, \& Fife, 1997). Argosy University/Atlanta continues to systematically develop its educational structure to improve the success of all students by training professors on effective strategies to create and facilitate cohorts.

\section{AUTHOR INFORMATION}

Angela D. Seay, As a desire to be a life-long learner, Angela's academic preparation began with a B S in Early Childhood Education from Concordia College, a MEd. in Educational Leadership \& Supervision from University of West Alabama, an EdS. in Curriculum \& Instruction from, and an EdD. in Instructional Leadership both from Argosy University.

Angela has obtained an array of professional leadership experience, as a Mentor for Teach One to Lead One, an Editor of dissertations, a Facilitator for research utilizing Standard Package of Social Sciences SPSS software, Site Facilitator, liaison for school and central office, served as chair of the following committees: Gradelevel, Grant Writing, Building Base Support Team, Parental Involvement, Curriculum Development, Professional Development, New Teacher/Mentoring Program, and Student/Teacher Motivation. She has extensive experience as a presenter of professional development activities at the local and state levels in the areas of reading/writing, student/teacher motivation, and classroom management. Angela also developed, implemented, and maintained professional learning communities while she mentored elementary and middle school students as a cheerleader coach.

The current area of focus is research, teacher education preparation, and learner motivation. As a Director of Field Experience at Concordia College - Selma, teaching education courses, teacher candidate preparation, and motivating learner are priorities.

\section{REFERENCES}

1. Breaux, A. (2003). 101 answers for New Teachers and Their Mentors. Eye on Education. Larchmont, NY.

2. Gold, C.M. (1994). Student descriptions of the doctoral student attrition process. Paper presented at the Annual Meeting of the Association for the Study of Higher Education. Tucson, AZ.

3. Green, K. E. (1995). Academic procrastination and perfectionism: A comparison of graduates and ABDs. Paper presented at the Annual Meeting of the American Educational Research Association. San Francisco.

4. Green, K. E., \& R. C. Kluever (1997). The dissertation barriers scale. Paper presented at the Annual Meeting of the American Education Research Association. Chicago. 
5. Joiner, R., Littleton, K., Faulkner, D., \& Miell, D. (2000). Rethinking collaborative learning. London Free Association Books.

6. Jonas, P. (2004). Secrets of connecting leadership \& learning with humor. Lanham, MD: Rowman \& Littlefield Publishing Group.

7. Katz, E. (1995). The dissertation: Academic interrupts. Paper presented at the Annual Meeting of the American Education Research Association. San Francisco.

8. Kluever. R. C. (1995). ABDs and graduates from a college of education: Responsibility, barriers and facilitators. Paper presented at the Annual Meeting of the American Educational Research Association. San Francisco.

9. $\quad$ Knowles, M. (1975). Self-Directed Learning. Chicago: Follet.

10. Knowles, M. (1984). The Adult Learner: A Neglected Species (3rd Ed.). Houston, TX: Gulf Publishing.

11. Knowles, M. (1984). Andragogy in Action. San Francisco: Jossey-Bass.

12. Kouzes, J., \& Posner, B. (2003). Exemplary leadership. San Francisco, CA: Jossey-Bass.

13. Lenz, K. (1995). Factors affecting the completion of the doctoral dissertation for non-traditional aged women. Paper presented at the Annual Meeting of the American Educational Research Association. San Francisco.

14. Levine, M. (2002). A Mind at a Time, New York.

15. Pratt, D., \& Brookfield, S. (2005). Five perspectives on teaching in adult and higher education. Malabar, FL: Krieger Publishing Company.

16. Sigafus, B. (1998). The creation of ABDs: a turning point in educational doctoral programs? Paper presented at the Annual Meeting of the American Research Association. San Diego. 


\section{$\underline{\text { NOTES }}$}

